\title{
REVIEW \\ Psychological resources in spinal cord injury: a systematic literature review
}

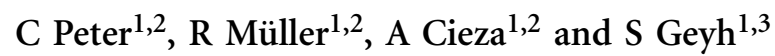

Study design: Systematic literature review.

Objectives: The purpose of this study was to gain a systematic overview of the role of psychological resources in the adjustment to spinal cord injury (SCI).

Methods: A systematic literature review was performed. The literature search was conducted in the databases Pubmed, PsyclNFO, the Social Sciences Citation Index, the Education Resources Information Center, Embase and the Citation Index of Nursing and Allied Health Literature. The assessed variables, measurement instruments, results and the methodological quality of the studies were extracted, summarized and evaluated.

Results: A total of 83 mainly cross-sectional studies were identified. Psychological resources were categorized into seven groups: self-efficacy (SE), self-esteem, sense of coherence (SOC), spirituality, optimism, intellect and other personality characteristics. SE and self-esteem were consistently associated with positive adjustment indicators such as high well-being and better mental health. Interrelations between psychological resources and key rehabilitation outcome variables such as participation were rarely studied. Only a few interventions, which were aimed at strengthening psychological resources were identified. Longitudinal studies suggested that SE, SOC, spirituality and purpose in life were potential determinants of adjustment outcomes in the long term.

Conclusion: Research on psychological resources in $\mathrm{SCl}$ is broad, but fragmented. Associations of psychological resources with mental health and well-being were frequently shown, while associations with participation were rarely studied. Further development of resource-based interventions to strengthen persons with $\mathrm{SCl}$ is indicated. This review can serve as guide for clinical practice and can add to the design of future $\mathrm{SCl}$ research.

Spinal Cord (2012) 50, 188-201; doi:10.1038/sc.2011.125; published online 29 November 2011

Keywords: psychological resource; spinal cord injuries; resilience; self-efficacy; quality of life; adjustment

\section{INTRODUCTION}

Spinal cord injury (SCI) involves severe physical, social, but also psychological consequences. ${ }^{1}$ The risk for major depression, anxiety disorder, post-traumatic stress disorder, substance abuse and suicide is elevated for people with SCI compared with the general population. ${ }^{2-7}$ Activating their inherent psychological resources may protect people with SCI from negative secondary consequences of the injury.

Psychological resources are inner, health protecting and health promoting potentials of a person, which represent a source or means to deal with difficult situations or obtain valued ends. ${ }^{8-11}$ They may include abilities, skills, knowledge, experiences, talents, strengths and behavioral patterns of the person. Strengthening psychological resources is an essential aim in clinical rehabilitation to support successful adjustment. ${ }^{12,13}$

Adjustment to disability is 'an evolving, dynamic, general process through which the individual gradually approaches an optimal state of person-environment congruence' (p. 8). ${ }^{14}$ Prevailing models for the understanding of adjustment following SCI stress the role of psychological, biological and environmental factors in determining adjustment outcomes such as well-being, mental health or participation via appraisal and coping processes. ${ }^{6,15-17}$ These models include psychological resources as determinants.
Current reviews in SCI have examined adjustment outcomes such as mental health and quality of life. ${ }^{5-7,18}$ In addition, external resources such as social support, ${ }^{19}$ and internal psychological resources such as locus of control ${ }^{20}$ and coping style ${ }^{18}$ have been implicated in adjustment outcomes but because of the unaccounted variance, there are perhaps a range of other psychological resources that could be contributing. A systematic overview of psychological resources in SCI does not exist yet. What is the current state of research on psychological resources, and what do we know about their relations to other factors and outcomes in the adjustment process following SCI? A summary of current findings on psychological resources could provide a basis for better understanding of adjustment, inform clinical practice, and could be used to develop and apply interventions tailored to strengthen people with SCI. To avoid redundancy with existing literature, ${ }^{5-7,18,20}$ this review has explicitly excluded social skills, coping and locus of control as potential psychological resources. They are only mentioned and discussed if their relation to the included psychological resources has been examined.

Therefore, the objective of this study is to systematically inquire about the role of psychological resources after SCI and examine their relationship with other factors and outcomes of the adjustment process. Specific aims are (a) to identify the psychological resources

${ }^{1}$ Swiss Paraplegic Research, Nottwil, Switzerland; ${ }^{2}$ Research Unit for Biopsychosocial Health, Institute for Health and Rehabilitation Sciences, Ludwig-Maximilians-University, Munich, Germany and ${ }^{3}$ Department of Health Sciences and Health Policy, University of Lucerne and SPF, Nottwil, Switzerland

Correspondence: C Peter, Guido A. Zäch-Strasse 4, CH-6207 Nottwil, Switzerland.

E-mail: claudio.peter@paranet.ch

Received 2 May 2011; revised 19 September 2011; accepted 23 September 2011; published online 29 November 2011 
studied in SCI research, and (b) to summarize the evidence about the relationship of psychological resources with other factors and outcomes of the adjustment process.

\section{MATERIALS AND METHODS}

A systematic literature review was performed searching Pubmed, PsycINFO, the Citation Index of Nursing and Allied Health Literature, the Social Sciences Citation Index and the Education Resources Information Center. Search terms for psychological resources were combined with search terms for SCI ('parap-

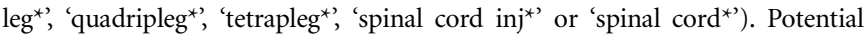
search terms for psychological resources were identified by consulting prominent health and health-related models and theories that address psychological resources, and by screening the psychological literature in PsycINFO for articles explicitly mentioning psychological resources in title or abstract. Potential search terms were checked for their correspondence with the definition of psychological resources to decide on their final use in the search strategy. (The list of all search terms is available as Supplementary Information on the webpage of the journal.)

Search results were screened for eligibility by two reviewers independently from each other, solving disagreement by consensus. Quantitative studies published in a scientific journal between 1990 and 2010 in English and mentioning psychological resources in the study aim, assessing psychological resources, or administering a psychological resource-based intervention were included for further analysis. Studies involving persons with SCI younger than 13 years, including non-human samples, and not generating first-hand data on psychological resources were excluded. Also, reviews, meta-analyses, dissertations, psychometric studies, case reports and qualitative studies were excluded.

Information about the study aims, design and population were extracted. from the included studies. All variables assessed in the study and the corresponding assessment instruments were identified. Among the study variables, all psychological resources were marked and study results about psychological resources were documented. For quality assurance, data extraction and study quality rating (see below) was conducted by two reviewers independently from each other in one-third of the articles, solving disagreement by consensus. Data extraction was conducted using an MS-Access database.

The identified psychological resources were listed and grouped. Research results were synthesized for each group thematically, subdivided by groups of associated variables representing outcomes and factors of the SCI adjustment process. Results were summarized considering the significance, direction, and the consistency of the associations, study methodology and strengths of evidence.

Study quality was rated using the Strengthening the Reporting of Observational Studies in Epidemiology (STROBE) Statement ${ }^{21}$ or the Physiotherapy Evidence Database Scale (PEDro). ${ }^{22}$ The STROBE represents a checklist of 22 criteria for case-control, cohort and cross-sectional studies. The PEDro scale consists of 11 items to be applied for randomized controlled trials. For both scales the number of fulfilled criteria per study was counted.

\section{RESULTS}

The literature search led to the identification of 1530 articles, 83 were included (Figure 1). The agreement between the reviewers was $92 \%$ for the paper selection, $69.7 \%$ for variables, $76.4 \%$ for results and $91 \%$ for study quality in the data extraction.

Study characteristics as well as demographic and lesion-related data of the study populations are depicted in Table 1. Overall, 92 different constructs representing psychological resources were captured in these studies (Table 2). Forty-eight of the search terms used were not identified in the literature search (for example, curiosity, humor or creativity). (See Supplementary Information on the webpage of the journal). Psychological resources were structured into seven overarching groups and both statistically significant and not significant results considered. Statistically significant results are presented in

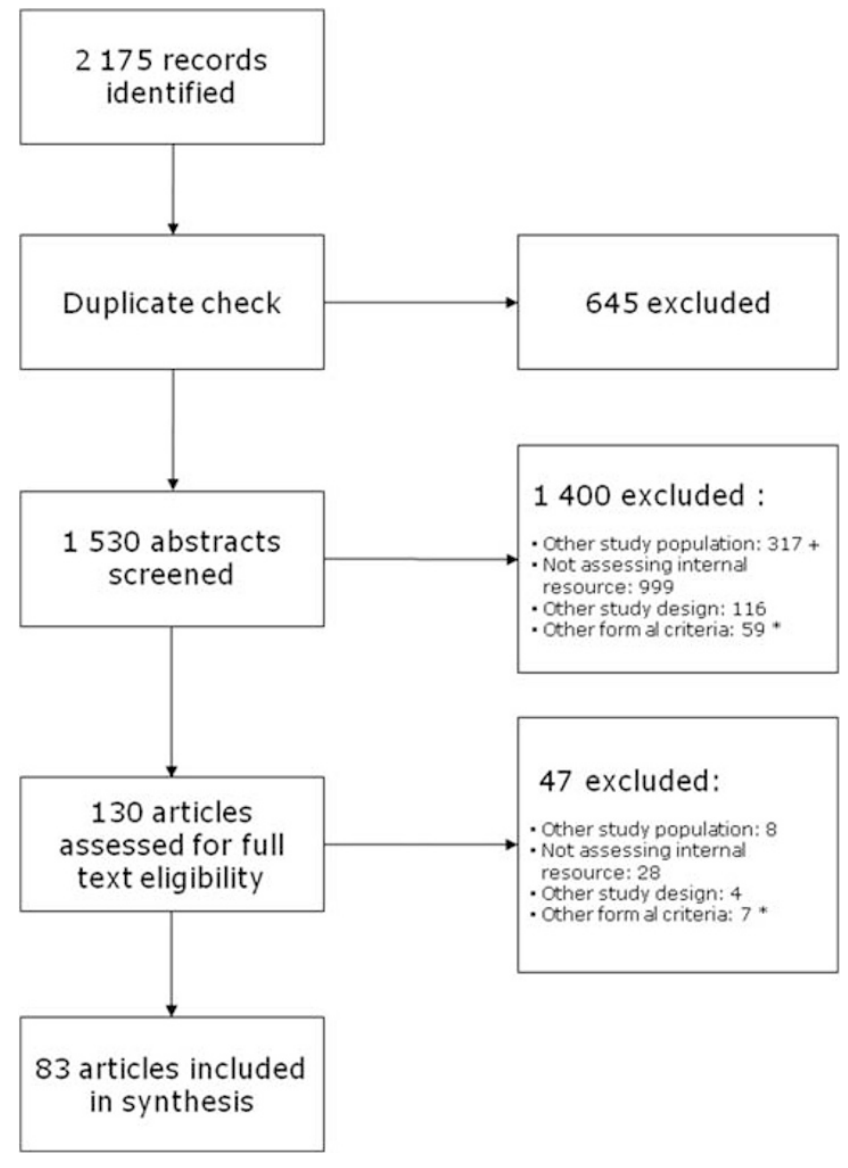

Figure 1 Flow diagram of the systematic literature review. + Numbers do not add up because several criteria can be applied to one article. *Other formal criteria: No abstract, not in English, other publication type, published before 1990.

Tables 3-6, while findings of this review are graphically summarized in Figure 2.

\section{Self-efficacy and perceived control}

Self-efficacy (SE) and perceived control (PC) are defined as the person's beliefs or general perceptions to direct or perform a behavior. $^{23,24}$ Overall, 7 studies assessed general self-efficacy (GSE), 12 studies self-efficacy related to health conditions or -management (HSE) and 6 studies SE related to other specific contents (for example, exercise). PC was assessed in 17 studies. Measurement instruments used are shown in Table 2.

Quality of life, well-being and life satisfaction. The evidence for the relation of SE with well-being seemed fairly strong. Persons with high GSE, social SE or PC reported higher well-being ${ }^{25-27}$ and life-satisfaction. $25,28,29$ The results regarding perceived health were inconclusive. ${ }^{25,26,29}$ HSE, but not GSE predicted quality of life in a multivariate longitudinal study. ${ }^{30}$ However, HSE's association with quality of life $\mathrm{e}^{30-32}$ and perceived health was inconsistent ${ }^{32,33}$ and may be explained by differences in the study populations.

Physical health. Only a few studies addressed the relation between SE and physical health, and the evidence appeared to be weak. People with higher HSE had less physical impairment ${ }^{34}$ and less secondary physical conditions ${ }^{35,36}$. PC over pressure relief did not predict health behavior for pressure sore prevention or pressure sore occurrence. 
Table 1 Characteristics of the 83 papers included in the systematic literature review

\begin{tabular}{|c|c|c|}
\hline & $(n=83)$ & $\%$ \\
\hline \multicolumn{3}{|l|}{ Country } \\
\hline USA & 44 & 52 \\
\hline Canada & 10 & 12 \\
\hline Australia & 7 & 8 \\
\hline United Kingdom & 6 & 7 \\
\hline Taiwan & 3 & 4 \\
\hline China & 2 & 3 \\
\hline Norway & 2 & 3 \\
\hline Sweden & 2 & 3 \\
\hline Switzerland & 1 & 1 \\
\hline Brazil & 1 & 1 \\
\hline Finland & 1 & 1 \\
\hline France & 1 & 1 \\
\hline Greece & 1 & 1 \\
\hline Italy & 1 & 1 \\
\hline Portugal & 1 & 1 \\
\hline South Korea & 1 & 1 \\
\hline \multicolumn{3}{|l|}{ Study design } \\
\hline Observational cross-sectional without control group & 28 & 33.5 \\
\hline Observational cross-sectional with control group & 28 & 33.5 \\
\hline Observational longitudinal without control group & 11 & 13 \\
\hline Intervention randomized controlled trial & 5 & 6 \\
\hline Intervention other & 4 & 5 \\
\hline Intervention controlled clinical trial & 4 & 5 \\
\hline Observational longitudinal with control group & 3 & 4 \\
\hline Sample size—mean (range) & 127( & 61) \\
\hline Age-mean (range) & 39.8 & 5.9) \\
\hline Not specified $(n)$ & 12 & \\
\hline \multicolumn{3}{|l|}{ Gender } \\
\hline Male & & 70.4 \\
\hline Female & & 29.6 \\
\hline Not specified $(n)$ & 8 & \\
\hline \multicolumn{3}{|l|}{ Marital status } \\
\hline Married $(n)$ & & 43.2 \\
\hline Not specified $(n)$ & 45 & \\
\hline Age at injury—mean (range) & $28.1(1$ & 42.2) \\
\hline Not specified $(n)$ & 62 & \\
\hline \multicolumn{3}{|l|}{ Severity of injury } \\
\hline Paraplegia & & 50.5 \\
\hline Tetraplegia & & 48.2 \\
\hline Complete injury & & 45.1 \\
\hline Incomplete injury & & 53.1 \\
\hline Traumatic injury & & 91.1 \\
\hline Non-traumatic injury & & 7.1 \\
\hline Time since injury in months_-mean (range) & 132( & 00) \\
\hline Not specified $(n)$ & 29 & \\
\hline \multicolumn{3}{|l|}{ Setting } \\
\hline Community based & 53 & 64 \\
\hline Mixed & 15 & 18 \\
\hline Inpatient & 9 & 11 \\
\hline Outpatient & 6 & 7 \\
\hline
\end{tabular}

However, sample size of this longitudinal study was low $(n=17) .{ }^{37}$ An inverse relation of exercise SE and breathing problems was reported. ${ }^{38}$

Pain may affect SE, however, evidence seems weak and is based on few studies. Pain SE was higher for persons with SCI than for pain patients without SCI. ${ }^{32}$ Persons with SCI and pain experienced lower HSE and exercise SE than persons without pain. ${ }^{33,38}$ High pain control was associated with less pain interference ${ }^{39,40}$ and lower pain intensity ${ }^{40}$ while inconsistent relationships of SE with these variables were found. ${ }^{32,33,38,41}$

Mental health. The associations of SE with mental health are the most consistent identified in this review. Persons with high GSE, HSE or pain control were consistently less anxious or depressed, ${ }^{32-34,38,41,42}$ and reported better mental health. ${ }^{39,40}$ However, these studies were cross-sectional and statements about the direction of relationships or causality cannot be made.

High HSE was associated with lower helplessness, ${ }^{34}$ but not related with feeling worn out, ${ }^{36}$ psychiatric history ${ }^{34}$ or number of medications $^{34}$ in cross-sectional studies. High exercise SE was related with higher alcohol consumption. ${ }^{38}$

Activity and participation. The evidence on the relation of SE with participation is fragmented, as different activity-types were examined. Persons with high GSE, HSE, exercise SE/mastery or PC performed more school, ${ }^{43}$ recreation ${ }^{25}$ or exercise activities ${ }^{44,45}$ prior or postinjury. They performed better health behavior and used less healthcare services, ${ }^{36}$ experienced more functional independence and less mobility restrictions. ${ }^{29}$ These belief-related resources were related with a higher amount of work activity prior injury ${ }^{43}$ and with more time spent on work post-injury. ${ }^{25}$ Associations with employment status were inconsistent, ${ }^{26,34,36}$ while the relationship with work impairment was not significant. ${ }^{29}$ Social integration, ${ }^{29}$ participation in SCIadapted activities ${ }^{36}$ and physical activity were not consistently higher for persons with high PC or HSE in cross-sectional and longitudinal studies. ${ }^{46,47}$

Sociodemographic and lesion-related variables. Evidence is fairly strong that SE and PC are not related with sociodemographic and lesion-related variables. Associations of belief-related resources with sociodemographic variables such as education, ${ }^{25,26,31,34,36,41}$ gender, $^{25,26,31,36}$ age, ${ }^{25,26,29,31,36,41,46,48}$ marital status, ${ }^{25,26,36,49}$ income ${ }^{25,26}$ and ethnicity ${ }^{26,28,36}$ were largely not significant.

The relationship of SE with lesion-related variables including level and completeness of injury, age at injury and time since injury were mostly not statistically significant. ${ }^{25,26,29,31,41,45,46}$ High HSE appears to be associated with greater time since injury. ${ }^{31,41} \mathrm{PC}$ was predicted by neurologic impairment one year post-injury in a multivariate analysis. ${ }^{43}$

Compared with general populations, persons with SCI reported lower social SE but equal GSE and PC, ${ }^{27,50}$ and higher HSE than persons with multiple sclerosis. ${ }^{34}$ Decreases in control and self-reliance because of SCI were retrospectively reported, ${ }^{51,52}$ but also increases in SE. ${ }^{53}$

Interrelations of psychological resources, appraisal and coping. Many different personal and environmental factors have been examined, but results are not comparable across studies and evidence remains weak. Persons with high control or mastery had more knowledge $\mathrm{e}^{43}$ and higher self-esteem. ${ }^{54}$ Higher HSE was associated with acceptance ${ }^{32,33}$ and fewer cognitive distortions. ${ }^{34}$ GSE positively correlated with perceived manageability. This might be explained by the conceptual similarity of these two variables. ${ }^{42}$ A person's PC at rehabilitation admission predicted PC 1-year post-injury. ${ }^{43}$ 
Table 2 Selected overarching groups of psychological resources, corresponding variables and measurement instruments

Overarching group of psychological resource

(total number of studies), specific resource
The General Self-Efficacy Scale ${ }^{141}$

General Self-Efficacy Scale ${ }^{142}$

Perceived Benefit Scale 143

Self-Efficacy for Managing Chronic Disease ${ }^{144}$

Self-rated Abilities for Health Practices Scale ${ }^{145}$

The Perceived Health Competence Scale ${ }^{146}$

Pain Self-Efficacy Questionnaire ${ }^{147}$

Moorong Self-Efficacy Scale ${ }^{148}$

The Beliefs Scale ${ }^{149}$

Items constructed/adapted by authors

Stanford Self-efficacy for Managing Chronic Disease Scale ${ }^{144}$

Items constructed/adapted by authors

Items constructed/adapted by authors

Items constructed/adapted by authors

SCI Exercise Self-Efficacy Scale ${ }^{151}$

Items constructed/adapted by authors

Items constructed/adapted by authors

Self-Efficacy in Active Living ${ }^{57}$

Items constructed/adapted by authors

The Self-Efficacy Scale ${ }^{141}$

Multi-dimensional Personality Questionnaire ${ }^{152}$

Self-Perception Scale ${ }^{51}$

Self-Perception Scale ${ }^{51}$

Mastery Scale ${ }^{154}$

Survey of Pain Attitudes ${ }^{155}$

Survey of Pain Attitudes-Short form ${ }^{156}$

Personal Independence Profile ${ }^{157}$

Perceived Stress Scale ${ }^{158}$

Seven-item measure of control-related constructs ${ }^{159}$

Self-Perception in Exercise Questionnaire ${ }^{160}$

Leisure Diagnostic Battery ${ }^{162}$

Internal-External Locus of Control Scale ${ }^{164}$

Items constructed/adapted by authors

Items constructed/adapted by authors
Study reference

25-28

$30,38,42$

53

41

60

30

32,59

31-33, 59

34

49

150

36

35

47, 58

38

44

47,58

56,57

44

27

153

51

51

54

40

39

$43,50,55$

29

46,47

45, 161

163

63

37

37

Perceived behavioral control of pressure sore

Self-esteem (20)

Self-esteem

Rosenberg Self-Esteem Scale ${ }^{61}$

Culture-Free Self-Esteem Inventory ${ }^{166}$

Index of Self-Esteem ${ }^{167}$

Culture-Free Self-Esteem Inventory ${ }^{166}$

Culture-Free Self-Esteem Inventory 166

Sexuality Scale ${ }^{168}$

Self-Perception Scale ${ }^{51}$

No information in article

Individualism-Collectivism scale ${ }^{169}$

Self-Perception Profile ${ }^{170}$

SCI Women Questionnaire ${ }^{69}$

$50,54,62-64,66-68,71,72,75,165$

$51,65,70$

73

70

70

63

51

56

28

74

69

Sense of Coherence Scale $\mathrm{e}^{76}$

Purpose in Life Scale ${ }^{171}$

$86,87,90$

Purpose in Life Scale ${ }^{171}$

85

Life regard Scale ${ }^{172}$ 
Table 2 (Continued)

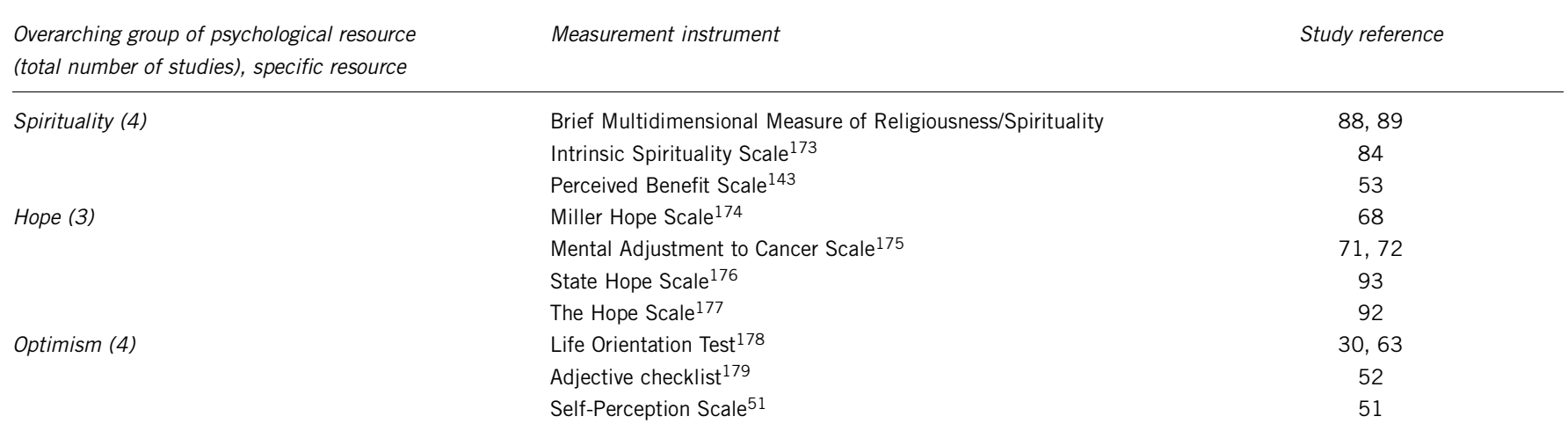

Abbreviations: GSE, general self-efficacy; HSE, health-related self-efficacy; PC, perceived control; SCl, spinal cord injury.

Environmental factors. Interpersonal support was unrelated to $\mathrm{PC}^{29}$ and inconsistently associated with HSE. ${ }^{36,41}$ HSE was unrelated to environmental adaptations, facility accessibility and denied/ unrequested health-care services. ${ }^{36}$ In-patients needing independent living services reported lower control than others. ${ }^{55}$

Interventions strengthening $S E$ and $P C$. Evidence regarding SE enhancement is fairly consistent. Multidisciplinary, multimodal interventions with different topics such as lifestyle or self-relaxation targeting specific SE were successful. GSE and specific SE, for example, for active living, were enhanced by active/independent living programs, ${ }^{56,57}$ or physical activity or sports programs. ${ }^{42,47,58}$ HSE was not increased by a cognitive-behavioral pain management program, ${ }^{59}$ but enhanced in a wellness workshop intervention. However, in the latter study, the enhanced HSE levels of persons in the intervention group did not differ from the HSE levels of the control group. ${ }^{60} \mathrm{PC}$ was not improved in the identified intervention studies. ${ }^{43,47,55}$ Overall, sample sizes for SE-intervention studies were small $(27<n<44)$, but larger for PC-intervention studies $(37<n<234)$.

\section{Self-esteem}

Self-esteem refers to a person's positive evaluation of one's self ${ }^{61}$ and was assessed in 20 studies (Table 4). Results are fragmented, but suggested relationships of self-esteem with well-being, mental health and participation. Persons with high self-esteem showed higher life satisfaction, ${ }^{54,62}$ better sexual adjustment, ${ }^{63}$ were less depressed, ${ }^{51,54}$ less stressed ${ }^{64}$ and felt less lonely. ${ }^{62}$ Self-esteem was inconsistently related to functional independence $e^{54,64,65}$ and not associated with scoliosis, ${ }^{65}$ or pressure sore occurrence. ${ }^{66}$ High self-esteem was associated with better social integration ${ }^{64}$ and related to physical, but not work- or school-related activities. ${ }^{67}$ Persons with high self-esteem experienced higher mastery ${ }^{54}$ and hope ${ }^{68}$ and showed more emotional- and problem-focused coping. ${ }^{64}$

Persons with SCI frequently perceived self-esteem as compromised by SCI. ${ }^{51,69,70}$ However, their self-esteem did not consistently differ from general ${ }^{50,54,71-73}$ or other clinical populations $(n=16) .{ }^{74}$ Crosssectional studies indicated that self-esteem could be restored. ${ }^{68,70}$ Longitudinal research reported reduced self-esteem 1 and 2 years post-injury. ${ }^{71,72}$ Self-esteem's association with gender was inconsistent; ${ }^{62,65,68}$ relations with other sociodemographic ${ }^{62,68,70}$ and lesionrelated variables. ${ }^{67,70}$ were not significant.

It was also inconsistently related with social support, ${ }^{62,64,65,68}$ unrelated to social barriers, ${ }^{64}$ but negatively connected to amount, origin and type of received insurance benefits. ${ }^{66,67}$
Self-esteem and self-affirmation were not enhanced by cognitive behavioral therapy ${ }^{75}$ or an educational active living-workshop. ${ }^{56}$ However, sample sizes were small in the treatment groups $(n=27$; $n=28$, respectively) and only few persons with low self-esteem participated. $^{75}$

\section{Sense of coherence}

Sense of coherence (SOC), defined as global orientation to view the world as comprehensible, manageable and meaningful, ${ }^{76}$ was measured in five studies (Table 4). SOC was associated with better psychosocial adjustment, ${ }^{77,78}$ and predicted better mental health ${ }^{78}$ and quality of life ${ }^{79}$ in longitudinal studies.

Persons with SCI reported changes in SOC after SCI, ${ }^{78}$ but higher SOC than able-bodied. ${ }^{80}$ High SOC was related to the coping strategies acceptance, ${ }^{78,79}$ fighting spirit ${ }^{79}$ and less social reliance, as well as to loss- and threat-appraisals. ${ }^{79}$

SOC of participants of a comprehensive pain management program ( $n=27)$ remained stable over 12 months. In contrast, SOC of persons with SCI in the control group without treatment decreased over time. $^{81}$

\section{Spirituality and purpose in life}

Spirituality, which refers to searching for or personal attitude toward transcendence, was assessed in four studies. ${ }^{82}$ Purpose in life (PIL) is the degree to which an individual finds meaning in life $\mathrm{f}^{83}$ and was examined in five studies (Table 5).

Associations of PIL and spirituality with well-being and mental health appear significant. However, evidence is weak and based on single studies. High spirituality and PIL were associated with higher life satisfaction and well-being, ${ }^{63,84,85}$ better mental health ${ }^{84}$ and adjustment $^{86}$ and, as shown in longitudinal research, reduced mortality. ${ }^{87}$ Spirituality was not associated with functional independence. ${ }^{84}$

Both, cross-sectional and longitudinal studies indicated changes in spirituality after SCI, ${ }^{53,84}$ and similar spirituality levels to persons with other health conditions. ${ }^{88,89}$ One large study reported significant but low correlations of PIL with health locus of control and various personality attributes. ${ }^{86}$

Higher PIL was found for men than women. ${ }^{90}$ Associations with other sociodemographic or lesion-related variables were statistically not significant. ${ }^{85,86}$

\section{Hope and optimism}

Hope and optimism conceptualized as positive orientation toward the future $^{91}$ were assessed in five cross-sectional and two longitudinal 
Table 3 Associations of self-efficacy with variables, type of analysis and corresponding coefficient

\begin{tabular}{|c|c|c|c|c|}
\hline Psychological resource & Associated variable & $\begin{array}{l}\text { Type of } \\
\text { analysis }\end{array}$ & Coefficient & Study reference \\
\hline Self-efficacy & Mental health & & & \\
\hline GSE, HSE & Anxiety & Corr & $r=-0.45$ to -0.515 & 33,42 \\
\hline GSE, HSE, exercise SE & Depression & Corr & $r=-0.43$ to $-0.611,+$ & $32-34,38,41-42$ \\
\hline HSE, exercise SE & Depression & Regr & $\beta=-0.28$ to $-0.35,+$ & 34,38 \\
\hline $\mathrm{HSE}^{\mathrm{a}}$ & Depression & Regr & $\beta=-0.263$ & 41 \\
\hline \multirow[t]{2}{*}{ PC (pain control) } & Mental health & Corr & $r=0.46$ to 0.55 & 39,40 \\
\hline & Mental health & Regr & $\beta=0.42$ & 40 \\
\hline HSE & Helplessness & Corr & $r=-0.47$ & 34 \\
\hline GSE, exercise SE & Alcohol consumption & Corr & + & 38 \\
\hline \multirow[t]{2}{*}{ Exercise SE ${ }^{a}$} & Alcohol consumption & Regr & + & 38 \\
\hline & Well-being and perceived health & & & \\
\hline GSE, PC & Life satisfaction & Corr & $r=.050$ to 0.52 & 25,29 \\
\hline GSE, PC & Life satisfaction & Regr & $\beta=0.36$ to $0.40,+$ & $25,28,29$ \\
\hline GSE, PC & Perceived health & Corr & $r=-0.216$ to 0.45 & $25,26,29$ \\
\hline \multirow[t]{3}{*}{ HSE } & Quality of life & Corr & $r=0.38$ to 0.73 & 30,31 \\
\hline & Quality of life & Regr & $\beta=0.265$ to 0.312 & 30 \\
\hline & Quality of life & (M)ANOVA & $F(8,97)=10.7, p<0.001$ & 31 \\
\hline GSE, social SE, PC & Well-being & Corr & $r=0.30$ to $0.43,+$ & $25-27$ \\
\hline \multirow[t]{2}{*}{ Social SE } & Well-being & Regr & $\beta=0.21$ & 27 \\
\hline & Sociodemographic and lesion-rela & & & \\
\hline HSE & Time since injury & Corr & $r=0.18$ to 0.367 & 36,41 \\
\hline HSE $^{a}$ & Time since injury & Regr & $\beta=0.205$ & 41 \\
\hline $\mathrm{PC}^{\mathrm{a}}$ & Neurological impairment & Regr & + & 43 \\
\hline Social SE & $\mathrm{SCl}$ vs general population & Diff & $t=-2.34, p<0.05$ & 27 \\
\hline HSE & SCI vs Multiple Sclerosis & Diff & $t=-2.46(158), p<0.05$ & 34 \\
\hline SE & Change (increase after $\mathrm{SCl}$ ) & Desc & $26 \%$ Of participants & 53 \\
\hline PC & Change (before $\mathrm{SCl}$ vs after $\mathrm{SCl}$ ) & Diff & + & 51 \\
\hline Self-reliance & Change (before $\mathrm{SCl}$ vs after $\mathrm{SCl}$ ) & Diff & + & 52 \\
\hline \multirow[t]{2}{*}{ PC (1-year post-injury) ${ }^{a}$} & $\mathrm{PC}$ & Regr & $\beta=0.20$ & 43 \\
\hline & Physical health & & & \\
\hline HSE & Physical impairment & Corr & $r=-0.27$ & 34 \\
\hline \multirow[t]{2}{*}{ HSE } & Secondary phys. conditions & Corr & $r=-0.52$ to -0.13 & 35,36 \\
\hline & & Path & $\beta=-0.12$ & 36 \\
\hline \multirow[t]{2}{*}{ Exercise SE ${ }^{a}$} & Breathing problems & Regr & + & 38 \\
\hline & Pain & & & \\
\hline Pain SE & SCI vs pain-patients & Diff & $t(45)=-5.29, p<0.05$ & 32 \\
\hline Pain control & Pain intensity & Corr & $r=-0.38$ & 40 \\
\hline HSE & Pain intensity & Diff & $\mathrm{OR}=2.7$ & 31 \\
\hline \multirow[t]{2}{*}{ Pain control } & Pain interference & Corr & $r=-0.46$ to -0.53 & 39,40 \\
\hline & Pain interference & Regr & $\beta=-0.34$ & 40 \\
\hline \multirow[t]{2}{*}{$\mathrm{HSE}^{\mathrm{a}}$} & Pain interference & Regr & $\beta=-0.427$ & 41 \\
\hline & Activity and Participation & & & \\
\hline GSE & Recreation activity & Corr & $r=0.24$ & 25 \\
\hline $\mathrm{PC}^{\mathrm{a}}$ & School activity & Regr & + & 43 \\
\hline $\mathrm{SE}$, exercise mastery ${ }^{\mathrm{a}}$ & Exercise activity & Regr & $\beta=0.23$ to $0.41,+$ & 44,45 \\
\hline \multirow[t]{2}{*}{ HSE } & Health behavior & Corr & $r=0.19$ & 36 \\
\hline & Health behavior & Regr & $\beta=0.20$ & 36 \\
\hline \multirow[t]{2}{*}{ HSE } & Health-care use & Corr & $r=-0.16$ & 36 \\
\hline & Health-care use & Regr & $\beta=-0.20$ & 36 \\
\hline PC & Functional independence & Corr & $r=0.178$ & 29 \\
\hline PC & Mobility restrictions & Corr & $r=0.175$ & 29 \\
\hline GSE & Work activity & Corr & $r=0.35$ & 25 \\
\hline $\mathrm{PC}^{\mathrm{a}}$ & Work activity & Regr & + & 43 \\
\hline
\end{tabular}


Table 3 (Continued)

\begin{tabular}{|c|c|c|c|c|}
\hline Psychological resource & Associated variable & $\begin{array}{l}\text { Type of } \\
\text { analysis }\end{array}$ & Coefficient & Study reference \\
\hline & Personal and environmental factors & & & \\
\hline HSE & Cognitive distortions & Corr & $r=-0.37$ & 34 \\
\hline PC & Knowledge & Corr & $r=0.34$ to 0.38 & 43 \\
\hline GSE & Perceived manageability & Corr & $r=0.64$ to 0.77 & 42 \\
\hline PC (1-year post-injury) ${ }^{a}$ & PC & Regr & $\beta=0.20$ & 43 \\
\hline Mastery & Self-esteem & Corr & $r=0.51$ & 54 \\
\hline HSE & Denied health-care services & Corr & $r=-0.02$ to 0.10 & 36 \\
\hline HSE & Environmental adaptations & Corr & $r=0.18$ to 0.22 & 36 \\
\hline \multirow[t]{2}{*}{$\mathrm{PC}^{\mathrm{a}}$} & Need of independent living service & Diff & + & 55 \\
\hline & Intervention & & & \\
\hline \multirow[t]{3}{*}{ SE } & Intervention (pre- vs post-intervention) & Diff & $\begin{array}{l}t(16)=2.67, \mathrm{p}<0.05, \text { Cohen's } d=0.86 \\
\mathrm{P}<0.05, \text { Cohen's } d=1.05 ; Z=2.5, \mathrm{p}<0.05\end{array}$ & $42,56,57$ \\
\hline & Intervention (pre- vs post-intervention) & (M)ANOVA & $F(2,84)=6, p<0.01$, Cohen's $d=0.60$ & 58 \\
\hline & Intervention (treatment vs control) & ANCOVA & $F(1,32)=4.76, \mathrm{p}<0.05$, Cohen's $d=0.52$ & 47 \\
\hline
\end{tabular}

Abbreviations: ANCOVA, analysis of covariance; Cohen's d, measure of effect size; Corr, bivariate correlation; Desc, descriptive data analysis; Diff, bivariate difference test; GSE, general selfefficacy; HSE, health-related self-efficacy; (M)ANOVA: (multivariate) analysis of variance; OR, odds ratio; PC, perceived control; Regr, regression analysis; SCI, spinal cord injury; SE, self-efficacy; $r$, correlation coefficient; $\beta$, standardized beta-coefficient; + , result-coefficient(s) not described in the article. aPsychological resource is the dependent variable.

$r$, correlation coefficient; $\beta$, standardized beta-coefficient; + , r
Only statistically significant and consistent results are shown.

Table 4 Associations of self-esteem and sense of coherence with variables, type of analysis and corresponding coefficient

\begin{tabular}{|c|c|c|c|c|}
\hline Psychological resource & Associated variable & Type of analysis & Coefficient & Study reference \\
\hline \multicolumn{5}{|l|}{ Self-esteem } \\
\hline Self-esteem & Life satisfaction & Corr & $r=0.43$ to 0.65 & 54,62 \\
\hline Self-esteem & Sexual adjustment & Regr & $\beta=0.49$ & 63 \\
\hline Sexual self-esteem & Sexual adjustment & Regr & $\beta=0.58$ to 0.68 & 63 \\
\hline Self-esteem & Depression & Corr & $r=-0.56$ to -0.74 & 51,54 \\
\hline \multirow[t]{2}{*}{ Self-esteem } & Stress & Corr & $r=-0.49$ & 64 \\
\hline & Stress & Path & $\beta=-0.61$ & 64 \\
\hline Self-esteem & Loneliness & Corr & $r=-0.45$ & 62 \\
\hline Self-esteem & Mastery & Corr & $r=0.51$ & 54 \\
\hline \multirow[t]{2}{*}{ Self-esteem } & Hope & Corr & $r=0.91$ & 68 \\
\hline & Hope & Regr & $\beta=0.53$ & 68 \\
\hline \multirow[t]{2}{*}{ Self-esteem } & Coping (emotion and problem-focused) & Corr & $r=0.34$ to 0.37 & 64 \\
\hline & Coping_emotion-focused & Path & $\beta=0.76$ & 64 \\
\hline Self-esteem & Social integration & Corr & $r=0.54$ & 64 \\
\hline Self-esteem & Activities physical & Regr & $\beta=0.24$ to 27 & 67 \\
\hline Confidence ${ }^{a}$ & Change (before $\mathrm{SCl}$ vs after $\mathrm{SCl}$ ) & Diff & + & 51 \\
\hline \multirow[t]{2}{*}{ Self-esteem ${ }^{a}$} & Change (before $\mathrm{SCl}$ vs after $\mathrm{SCl}$ & Diff & $t(60)=4.58, p<0.01$ & 70 \\
\hline & 1 -year post-injury vs 2 -year post-injury vs 5 -year post-injury & (M)ANOVA & $p<0.01$ & 70 \\
\hline Self-esteem & Received insurance benefits & Regr & $\beta=-0.16$ to -0.38 & 67 \\
\hline \multicolumn{5}{|l|}{ Sense of coherence } \\
\hline \multirow[t]{2}{*}{ Sense of coherence } & Psychosocial adjustment & Corr & $r=0.31$ to 55 & 78 \\
\hline & Psychosocial adjustment & (M)ANOVA & + & 77 \\
\hline Sense of coherence & Mental health & Corr & $r=0.47$ to 63 & 78 \\
\hline Sense of coherence & Quality of life & Corr & $r=0.554$ & 79 \\
\hline Sense of coherence & Coping-acceptance & Corr & $r=0.59$ to 0.647 & 78,79 \\
\hline Sense of coherence & Coping_fighting spirit & Corr & $r=0.397$ & 79 \\
\hline Sense of coherence & Coping_-social reliance & Corr & $r=-0.493$ & 79 \\
\hline Sense of coherence & Appraisal_loss & Corr & $r=-0.542$ & 79 \\
\hline Sense of coherence & Appraisal-threat & Corr & $r=-0.488$ & 79 \\
\hline Sense of coherence & Appraisal—challenge & Corr & $r=0.283$ & 79 \\
\hline Sense of coherence ${ }^{a}$ & Change (before $\mathrm{SCl}$ vs after $\mathrm{SCl}$ ) & Desc & + & 78 \\
\hline Sense of coherence ${ }^{a}$ & $\mathrm{SCl}$ vs general population & Diff & $t(140)=2.92, p<0.05$ & 80 \\
\hline Sense of coherence ${ }^{a}$ & Intervention & Diff & + & 81 \\
\hline
\end{tabular}

Abbreviations: ANCOVA, analysis of covariance; Corr, bivariate correlation; Diff, bivariate difference test; Desc, descriptive data analysis; (M)ANOVA, (multivariate) analysis of variance; Path, path analysis; Regr, regression analysis; SCI, spinal cord injury; $r$, corr coefficient; $\beta$, standardized beta-coefficient; + , result-coefficient(s) not described in the article. aPsychological resource is the analysis; Regr, regress

Only statistically significant and consistent results are shown. 
Table 5 Associations of spirituality and hope with variables, type of analysis and corresponding coefficient

\begin{tabular}{|c|c|c|c|c|}
\hline Psychological resource & Associated variable & Type of analysis & Coefficient & Study reference \\
\hline \multicolumn{5}{|c|}{ Spirituality and purpose in life } \\
\hline Spirituality & Life satisfaction & Corr & $r=0.48$ to 0.60 & 84 \\
\hline Meaning & Well-being & Regr & $\beta=0.58$ to 0.73 & 63,85 \\
\hline Spirituality & Mental health & Corr & $r=r=-0.27$ to -0.42 & 84 \\
\hline \multirow[t]{2}{*}{ Meaning } & Adjustment & Corr & $r=0.50$ & 86 \\
\hline & Adjustment & Regr & + & 86 \\
\hline Purpose in life & Mortality & Surv. Anal. & $\mathrm{HR}=0.81$ & 87 \\
\hline \multirow[t]{2}{*}{ Spirituality } & Change (increase after $\mathrm{SCl}$ ) & Desc & $43 \%$ Of participants & 53 \\
\hline & Change (rehabilitation admission vs rehabilitation discharge) & ANCOVA & Cohen's $d=0.10$ & 84 \\
\hline Purpose in life & Locus of control & Corr & $r=-0.12$ to 0.22 & 86 \\
\hline Purpose in life & Gender & (M)ANOVA & $t(1,260)=2.11, p<0.05$ & 90 \\
\hline \multicolumn{5}{|l|}{ Hope and optimism } \\
\hline Hope & Functional independence & Corr & $r=0.33$ & 93 \\
\hline Optimism & Well-being & Regr & $\beta=0.68$ & 63 \\
\hline $\mathrm{Hope}^{\mathrm{a}}$ & Self-esteem & Corr & $r=0.91$ & 68 \\
\hline $\mathrm{Hope}^{\mathrm{a}}$ & Social support & Corr & $r=0.89$ & 68 \\
\hline Hope & Coping-acceptance & Corr & $r=0.53$ & 93 \\
\hline Hope & Coping_fighting spirit & Corr & $r=0.69$ & 193 \\
\hline Hope & Appraisal—threat & Corr & $r=-0.65$ & 93 \\
\hline Optimisma & Change (before $\mathrm{SCl}$ vs after $\mathrm{SCI}$ ) & Diff & + & 51,52 \\
\hline Hope $^{\text {a }}$ & Education & Regr & $\beta=0.162$ & 68 \\
\hline Hope $^{a}$ & Ethnicity & Diff & $t=2.18, p<0.05$ & 68 \\
\hline Hope & Time since mobilization & Corr & $r=-0.29$ & 93 \\
\hline Hope $^{\text {a }}$ & Patient status & Diff & $t=2.47, p<0.05$ & 68 \\
\hline
\end{tabular}

Abbreviations: ANCOVA, analysis of covariance; Cohen's d, measure of effect size; Corr, bivariate correlation; Desc, descriptive data analysis; Diff, bivariate difference test; HR, hazard ratio; (M)ANOVA, (multivariate) analysis of variance; Regr, regression analysis; SCl, spinal cord injury; Surv. Anal., survival analysis; $r$, correlation coefficient; $\beta$, standardized beta-coefficient; + , resultcoefficient(s) not described in the article. aPsychological resource is the dependent variable.

Only statistically significant and consistent results are shown.

studies $^{30,92}$ (Table 5). Evidence appears fragmented and contradictory. Hope and optimism showed positive bivariate relations with life satisfaction, ${ }^{92}$ quality of life, ${ }^{30}$ sexual well-being, ${ }^{63}$ mental health ${ }^{93}$ and functional independence. ${ }^{93}$ However, relations were not significant in multivariate, longitudinal analyses. ${ }^{30,92,93}$

Affected persons perceived optimism as compromised by SCI. ${ }^{51,52}$ Interconnections of hope with education and ethnicity, ${ }^{68}$ time since mobilization ${ }^{93}$ and in- or out-patient status were found. ${ }^{68}$ Relations with other sociodemographic or lesion-related variables were not significant. $^{93}$

High correlations of hope with self-esteem $(r=0.908)$ and social support $(r=0.891)$ were found, indicating potential conceptual overlap. ${ }^{68}$ Hopeful persons applied the coping strategies acceptance and fighting spirit more often than persons who were low on hope. They were also less likely to appraise their situation as a threat. ${ }^{93}$ Relationships of hope with social reliance coping, with control appraisals and challenge appraisals were statistically not significant. ${ }^{93}$

\section{Intellect, knowledge and competence}

Ten studies addressed intelligence and competence of persons with SCI (Table 6). The evidence on the role of intellect in the adjustment process is weak. Intelligence of persons with SCI did not differ from a matched control group. ${ }^{94}$ Verbal ability predicted disability acceptance at rehabilitation discharge in a longitudinal study. ${ }^{95}$ Verbal ability and memory capacity were related with age, but generally not with lesionrelated variables. ${ }^{48,95}$ A longitudinal study $(n=17)$ found high skin care knowledge predicting less pressure sore occurrence ${ }^{37}$ but not skin care behavior. The investigators of this study did not further elaborate on this counter-intuitive finding. Knowledge significantly correlated with PC after 1-year follow-up and was enhanced in a multi-modal intervention program. ${ }^{43}$

\section{Personality and motivation}

Personality is defined as characteristic patterns of thoughts, feelings and behaviors that make a person unique. Various personality attributes were assessed in 23 studies (Table 6). Overall, the evidence on the relation of personality characteristics with other variables is weak.

Major personality dimensions (the Big Five). Agreeableness, extraversion, conscientiousness, openness to experience and neuroticism are considered the five major personality dimensions (Big Five). Together, they explained variance of depression and predicted disability acceptance and problem solving. ${ }^{96}$

Lower conscientiousness, but equal agreeableness and extraversion levels ${ }^{97}$ were reported for people with SCI in comparison with normative ${ }^{97}$ and healthy samples. ${ }^{98}$ Extraverted persons reported less depression, ${ }^{96,98}$ (phobic) anxiety, ${ }^{98}$ or other psychopathological symptoms ${ }^{98}$ and rather participated in sports. ${ }^{99}$

Social traits. Forgiving persons reported higher life-satisfaction and were more educated. Associations with health (behavior), and other sociodemographic and lesion-related variables were inconsistent. ${ }^{100}$ High sociability was related with better adjustment, PIL and personality but not with locus of control or injury level. ${ }^{86}$ Persons with SCI thought they would be more sociable and understanding without 
Table 6 Associations of intellect and personality with variables, type of analysis and corresponding coefficient

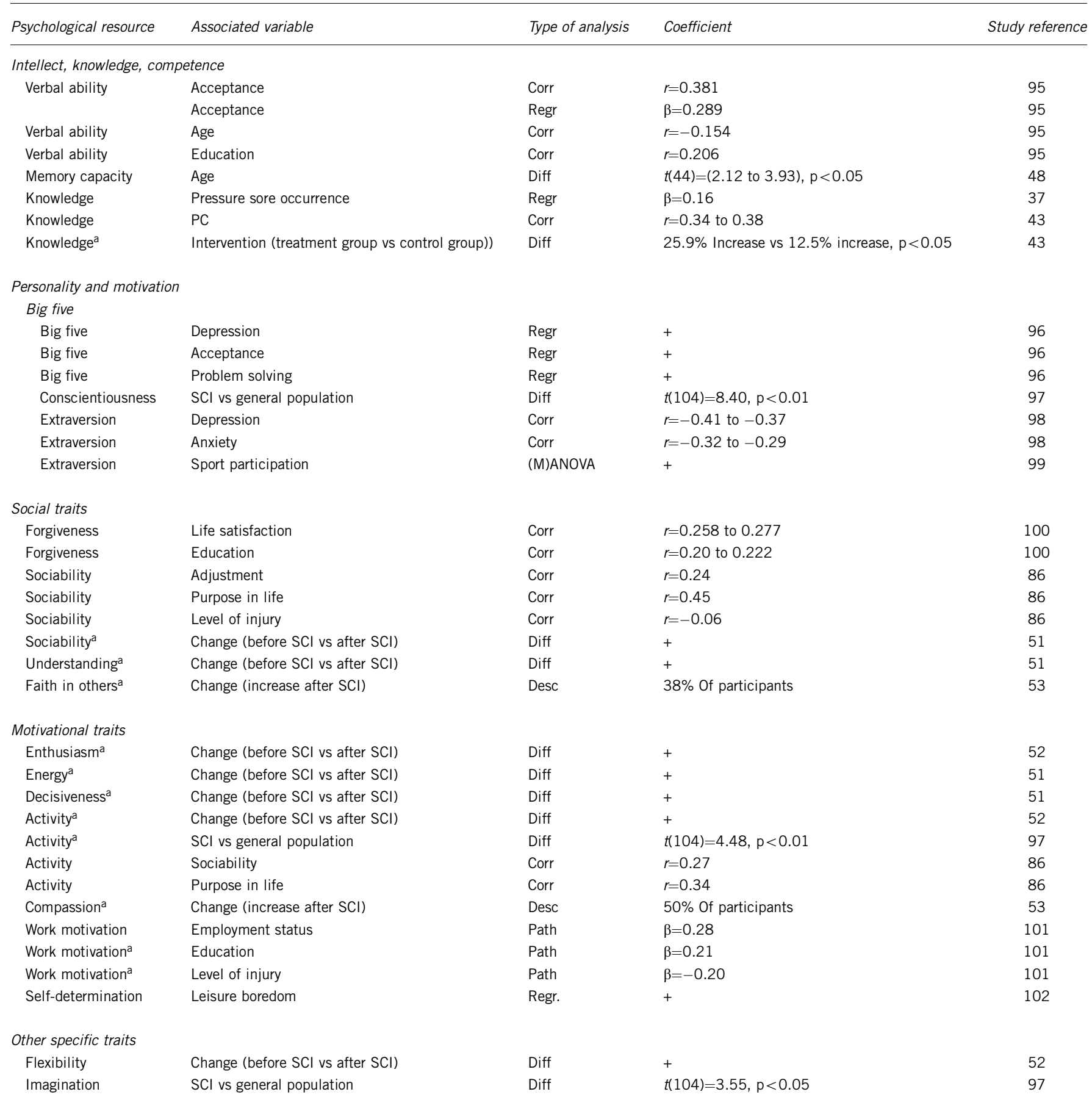

Abbreviations: ANCOVA, analysis of covariance; Corr, bivariate correlation; Desc, descriptive data analysis; Diff, bivariate difference test; (M)ANOVA, (multivariate) analysis of variance; Path, path analysis; Regr, regression analysis; SCI, spinal cord injury; Surv. Anal., survival analysis; $r$, correlation coefficient; $\beta$, standardized beta-coefficient; + , result-coefficient(s) not described in the article. apsychological resource is the dependent variable.

Only statistically significant and consistent results are shown.

SCI, ${ }^{51}$ reported increased faith in others ${ }^{53}$ and were as gregarious as a normative sample. ${ }^{97}$

Motivational traits. Persons with SCI indicated that the injury negatively affected their enthusiasm, ${ }^{52}$ energy, ${ }^{51}$ decisiveness ${ }^{51}$ and activity, ${ }^{52,97}$ but increased their compassion. ${ }^{53}$ Work motivation predicted employment status, was explained by education and lesion level, but not related with age at injury, driving ability, locus of control and social support in a study using unstandardized measurement instruments. ${ }^{101}$ People with high activity-orientation were more sociable and reported higher PIL. ${ }^{86}$ Self-determination was not related to leisure boredom. ${ }^{102}$ Leisure motivation did not increase in a sports program $(n=24) .{ }^{103}$

Other specific traits. People with SCI reported less flexibility since the injury. ${ }^{52}$ They were more imaginative than a normative sample. ${ }^{97}$ 


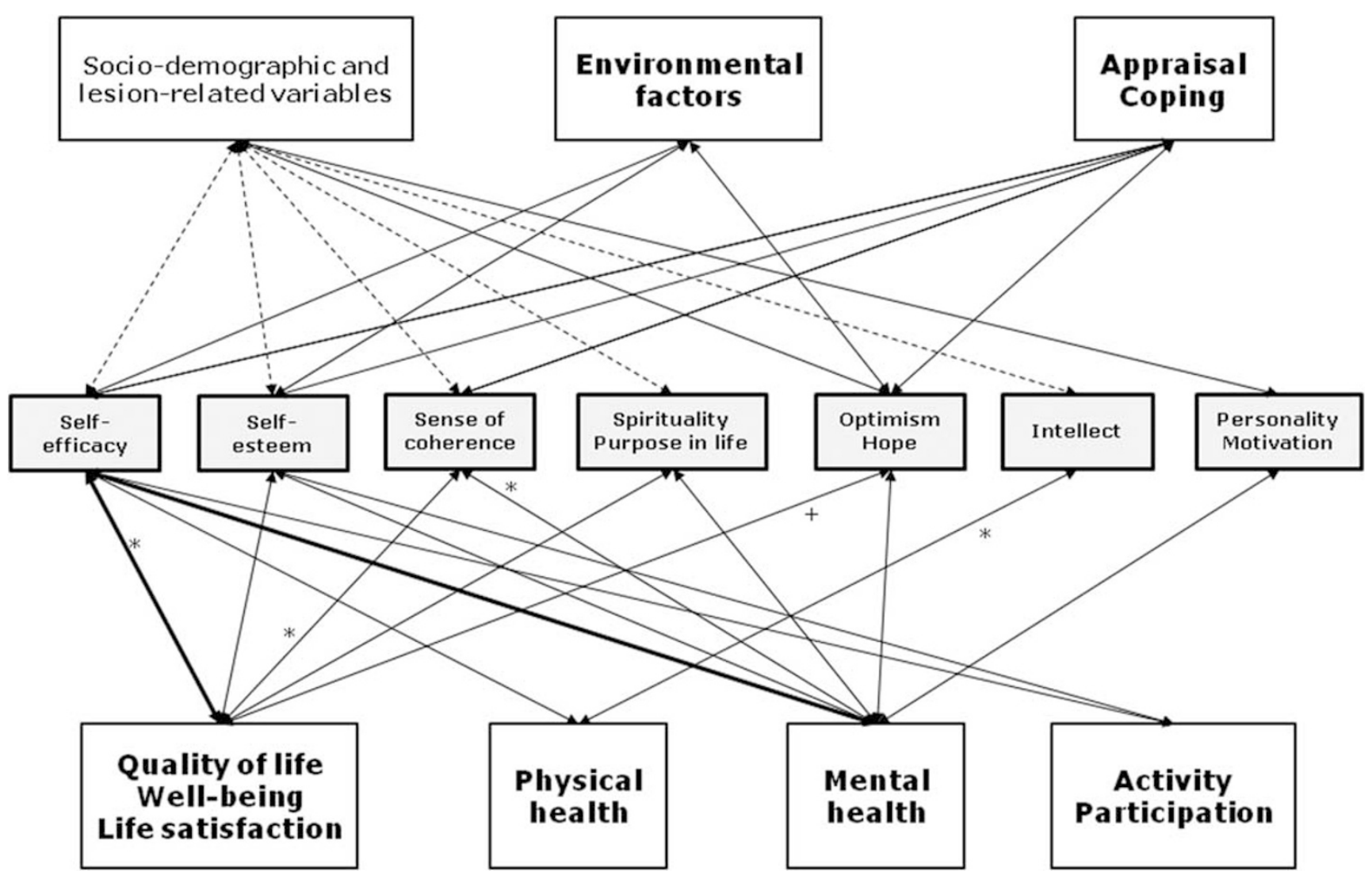

Figure 2 Associations between psychological resources and factors and outcomes of the adjustment process in SCI. Bold line: Association with strong evidence, several studies conducted consistent results shown. Normal line: Modest/weak evidence. Single studies with associated variable conducted, or inconsistent results found. Dotted line: No association, several studies conducted, consistent results shown. *: Psychological resource is predictor of the variable in a longitudinal study. +: Psychological resource is NOT a predictor of the variable in a longitudinal study. Interrelations of the selected psychological resources are not depicted in this figure.

Hardiness was not related with locus of control or ethnicity, but explained variance of self-concept dependent on ethnicity. ${ }^{104}$

\section{Study quality}

The evaluation of the studies' quality showed overall satisfying results. Case-control, cohort and cross-sectional studies were rated with STROBE and attained a score of 15 on average (range from 9 to 21 points). Abstracts, introduction, variable definition, presentation and interpretation of study results were mostly satisfactory. However, only few studies considered potential sources of bias (9\%), explained how the sample size was determined $(4 \%)$ or reported additional analyses (9\%).

Five randomized controlled trials were identified and rated with PEDro. ${ }^{35,47,56,58,60}$ On average, studies achieved a score of 7.4 out of 11. Therapists and assessors were not blinded and only two studies ${ }^{56,58}$ performed concealed allocation and 'intention to treat' analyses. ${ }^{22}$

Overall, the results are fragmented, frequently not comparable across studies, and therefore require replication. The identified studies suffer from potential problems in measurement robustness, low sample sizes and problems of sample representativeness, for example, by using convenience samples.

\section{DISCUSSION}

Research on psychological resources in SCI appears to be broad, but fragmented, and consists mainly of cross-sectional studies conducted in English-speaking countries. This review shows that psychological resources can be compromised by SCI, and are associated with various adjustment outcomes, particularly mental health and well-being, but not with sociodemographic and lesion-related variables.

SE, PC and self-esteem were frequently assessed. Fewer studies examined SOC, spirituality and PIL, optimism and hope, intelligence and personality. Relationships of psychological resources with coping, cognitive appraisals, activity and participation were rarely studied. Various psychological resources that were explicitly searched for in the literature were not identified in this review, although they might be important with regards to adjustment outcomes. For example, curiosity has a predictive role for the longevity of older adults ${ }^{105}$ and correlates positively with life satisfaction ${ }^{106}$ and well-being. ${ }^{107,108}$ In SCI, their role remains unclear.

The evidence for the relationship of SE and self-esteem with better mental health and higher well-being is fairly consistent in the SCI literature and in line with findings in other health conditions or the general population. ${ }^{109-114}$ However, little is known about changes over time, and the direction of relationships or potential causal mechanisms have not been studied. In one longitudinal study, SE predicted quality of life post-injury, suggesting that strengthening SE might enhance life quality. ${ }^{30}$

Evidence regarding associations of SE with other variables is to a large extent inconsistent or fragmented. Limiting the capacity to compare findings is the fact, that SE is not a homogeneous concept. Beside GSE, diverse specific constructs, like exercise SE, pain SE or social SE were assessed in single studies (Table 2). 
The review identified evidence for the relationship of SOC with SCI adjustment. SOC predicted mental health and was linked with coping and appraisal variables. ${ }^{93}$ The findings confirm the theoretical role of SOC as a salutogenetic factor and are in line with research across various populations and health conditions connecting SOC with psychological well-being ${ }^{115-118}$ or coping. ${ }^{119}$

Spirituality and PIL in persons with SCI were only assessed in few studies. However, cross-sectional as well as longitudinal findings suggest associations with better mental health, higher quality of life and reduced mortality. These results are in line with research with populations with other health conditions such as human immunodeficiency virus or Alzheimer disease or healthy populations. ${ }^{120-129}$ Spirituality can be an important component in psychotherapy. ${ }^{130-132}$ Beneficial effects of meaning making interventions on SE, optimism and self-esteem are reported. ${ }^{133}$

The review of the literature suggests that people with SCI who are hopeful and optimistic are also more satisfied and less depressed. ${ }^{30,63,92,93}$ However, this relationship did not hold in longitudinal studies. ${ }^{30,92,93}$ It could be hypothesized that hope and optimism support the affected people during rehabilitation while other resources might become more important after rehabilitation discharge. A second assumption could be that coping might mediate the long-term effect of optimism, because optimistic persons tend to use different coping strategies from pessimists. ${ }^{134}$ Longitudinal multivariate studies are required to test these assumptions.

Only few intervention studies were identified that aimed at strengthening psychological resources. Testing psychological interventions and conducting randomized controlled trials in rehabilitation settings remains challenging. ${ }^{135}$ SE was the only psychological resource, which was enhanced in multi-content intervention studies conducted with persons with SCI living in the community. ${ }^{42,47,56-58}$ This is consistent with research in other chronic health conditions, where SE interventions that adopt various strategies such as the use different modes of learning or the involvement of significant others proved to be useful. ${ }^{136,137}$ Other studies might have failed to report similar results because of low sample sizes, underpowered analyses or because the interventions were not appropriately targeted (for example, for persons with low self-esteem).

Most studies on psychological resources have been conducted in the community but not in the clinical setting. It remains unclear whether psychological resources are more important in the short or long term. Thus, early detection and long-term follow-up in longitudinal studies would be valuable.

Overall, the associations found between psychological resources and other variables need to be interpreted with caution, because they might be the result of conceptual overlap. For example, certain spirituality questionnaires contain items referring to emotional wellbeing, which would explain consistent correlations of spirituality with well-being. ${ }^{138}$ Research of psychological resources could be enhanced by a clearer and more differentiated conceptualization and operationalization of the various factors.

This literature review is subject to several limitations. The search strategy as well as the selection of the literature depended on a rather narrow definition of the term 'psychological resource' as concepts that are positively valued in themselves. In contrast, resources are often defined in a broader sense by their effect and include any means that serve to achieve a positively valued end. Therefore, the list of psychological resources, which guided this review could be debated and might not be fully exhaustive. Furthermore, social skills, locus of control and coping, which are psychological resources, have not been considered, because current reviews summarizing findings about these factors have been published in SCI. ${ }^{18-20}$ It is important to note that coping was only mentioned if it was associated with one of the psychological resources, which we have included. Consequently, the results of this review do not represent the whole picture of current knowledge on coping in SCI.

This review conveys a broad overview of the associations of psychological resources with factors and outcomes of the SCI adjustment process, but does not contain an in-depth analyses of specific aspects. Finally, this study focused only on quantitative research. A systematic review of qualitative studies could provide a complementary and more in-depth view for the understanding of psychological resources in persons with SCI.

A number of conclusions can be drawn from the findings of this review considering possible directions for future research. First, to achieve a less fragmented and more comprehensive understanding of the role of psychological resources and their complex interplay with other factors, appropriate data collection and analyses methods are required, that is, the assessment of potential confounding variables and the use of multivariate analyses. Second, with regard to outcome variables, behavioral and social outcomes such as participation and integration were found to be rarely studied in relation to psychological resources in people with SCI. As participation and integration represent key outcomes of rehabilitation, further research would be warranted. Third, little is known about the changes in psychological resources across time following SCI and about the direction of effects in relation to other factors. However, longitudinal studies hinted at SE, SOC, spirituality and PIL as potential variables affecting adjustment outcomes in the long term. Therefore, multivariate longitudinal research could provide further insights. Fourth, potentially useful psychological resources, such as curiosity ${ }^{105,106}$ or humor, ${ }^{139}$ are underrepresented in SCI research, and could be targets for further exploration. Finally, only few intervention studies were identified. However, studies suggest that strengthening SE, for example, could have a positive effect on quality of life. ${ }^{30}$ The development and testing of targeted psychological resource-based interventions could benefit people with SCI and represent worthwhile research efforts.

This review emphasizes and provides insight into the role of psychological resources in the SCI adjustment process. It can inform health professionals who adopt a resource-oriented, person-centered approach in both the clinical and the community setting, and can add to the design of future SCI research.

\section{CONFLICT OF INTEREST}

The authors declare no conflict of interest.

\section{ACKNOWLEDGEMENTS}

This project has been funded by the Swiss Paraplegic Research (SPF) in Nottwil, Switzerland.

1 Kirshblum S, Campagnolo DI, DeLisa JA. Spinal Cord Medicine. Lippincott Williams and Wilkins: Philadelphia, 2002.

2 DeVivo MJ, Black KJ, Richards S, Stover SL. Suicide following spinal cord injury. Paraplegia 1991; 29: 620-627.

3 Beedie A, Kennedy P. Quality of social support predicts hopelessness and depression post spinal cord injury. J Clin Psychol Med Settings 2002; 9: 227-234.

4 Kennedy P, Rogers BA. Anxiety and depression after spinal cord injury: a longitudinal analysis. Arch Phys Med Rehabil 2000; 81: 932-937.

5 North NT. The psychological effects of spinal cord injury: a review. Spinal Cord 1999; 37: 671-679.

6 Galvin LR, Godfrey HP. The impact of coping on emotional adjustment to spinal cord injury $(\mathrm{SCl})$ : review of the literature and application of a stress appraisal and coping formulation. Spinal Cord 2001; 39: 615-627. 
7 Craig A, Tran Y, Middleton J. Psychological morbidity and spinal cord injury: a systematic review. Spinal Cord 2009; 47: 108-114.

8 Rowe MA. The impact of internal and external resources on functional outcomes in chronic illness. Res Nurs Health 1996; 19: 485-497.

9 Udris I, Kraft U, Mussmann C, Rimann M. Arbeiten, gesund sein und gesund bleiben: Theoretische Überlegungen zu einem Ressourcenkonzept. In I. Udris (eds.), Arbeit und Gesundheit. Psychosozial, Band 52 (p 9-22). Weinheim: Psychologie Verlags Union.

10 Luria G, Torjman A. Resources and coping with stressful events. J Organ Behav 2009; 30: 685-707.

11 Hobfoll SE. Social and psychological resources and adaptation. Rev Gen Psychol 2002; 6: 307-324.

12 Berkman B, Bonande RE, Rutchick I, Silverman P, Kemler B, Marcus L et al. Social work in health care: directions in practice. Soc Sci Med 1990; 31: 19-26.

13 Flückiger C, Wüsten G, Zinbarg RE, Wampold BE. Resource Activation: Using Clients' Own Strengths in Psychotherapy and Counseling. Hogrefe Publishing: Cambridge, MA, 2010.

14 Livneh H, Antonak RF. Psychosocial Adjustment to Chronic IIIness and Disability. Aspen Publishers, Inc.: Gaithersburg, MD, 1997.

15 Middleton J, Craig A. Psychological challenges in treating persons with spinal cord injury. In: Craig A, Tran Y (eds). Psychological Aspects Associated with Spinal Cord Injury Rehabilitation: New Directions and Best Evidence. Nova Science Publishers, Inc.: New York, 2008.

16 Lazarus RS, Folkman S. Stress, Appraisal and Coping. Springer: New York, 1984.

17 Craig A, Tran Y. Psychological Dynamics Associated with Spinal Cord Injury Rehabilitation: New Directions and Best Evidence. Nova Publications: New York, 2008

18 Chevalier Z, Kennedy P, Sherlock O. Spinal cord injury, coping and psychological adjustment: a literature review. Spinal Cord 2009; 47: 778-782.

19 Müller R, Peter C, Cieza A, Geyh S. Social support and social skills in spinal cord injury - a systematic review of the literature. Spinal Cord 2011; (e-pub ahead of print).

20 Waldron B, Benson C, O'Connell A, Byrne P, Dooley B, Burke T. Health locus of control and attributions of cause and blame in adjustment to spinal cord injury. Spinal Cord 2010; 48: 598-602.

21 Vandenbroucke JP, von Elm E, Altman DG, Gotzsche PC, Mulrow CD, Pocock SJ et al. Strengthening the Reporting OF Observational Studies in Empidemiology (STROBE): explanation and elaboration. PLOS Med 2007; 4: 1628-1654.

22 Verhagen AP, de Vet HC, de Bie RA, Kessels AG, Boers M, Bouter LM et al. The Delphi list: a criteria list for quality assessment of randomised clinical trials for conducting systematic reviews developed by Delphi consensus. J Clin Epidemiol 1998; 51: 1235-1241

23 Bandura A. Self-efficacy: toward a unifying theory of behavioral change. Psychol Rev 1977; 84: 191-215.

24 Rodgers WM, Conner M, Murray TC. Distinguishing among perceived control, perceived difficulty, and self-efficacy as determinants of intentions and behaviours. Br J Soc Psychol 2008; 47: 607-630.

25 Hampton NZ. Self-efficacy and quality of life in people with spinal cord injuries in China. Rehabil Counsel Bull 2000; 43: 66-74.

26 Hampton NZ. Subjective well-being among people with spinal cord injuries: the role of self-efficacy, perceived social support, and perceived health. Rehabil Counsel Bull 2004; 48: 31-37.

27 Hampton NZ. The affective aspect of subjective well-being among Chinese people with and without spinal cord injuries. Disabil Rehabil 2008; 30: 1473-1479.

28 Hampton NZ, Marshall A. Culture, gender, self-efficacy, and life satisfaction: a comparison between Americans and Chinese people with spinal cord injuries. J Rehabil 2000; 66: 21-28.

29 Fuhrer MJ, Rintala DH, Hart KA, Clearman R, Young ME. Relationship of life satisfaction to impairment, disability, and handicap among persons with spinal cord injury living in the community. Arch Phys Med Rehabil 1992; 73: 552-557.

30 Mortenson WB, Noreau L, Miller WC. The relationship between and predictors of quality of life after spinal cord injury at 3 and 15 months after discharge. Spinal Cord 2010; 48: 73-79.

31 Middleton J, Tran Y, Craig A. Relationship between quality of life and self-efficacy in persons with spinal cord injuries. Arch Phys Med Rehabil 2007; 88: 1643-1648.

32 Nicholson Perry K, Nicholas MK, Middleton J, Siddall P. Psychological characteristics of people with spinal cord injury-related persisting pain referred to a tertiary pain management center. J Rehabil Res Dev 2009; 46: 57-67.

33 Nicholson Perry K, Nicholas MK, Middleton J. Spinal cord injury-related pain in rehabilitation: a cross-sectional study of relationships with cognitions, mood and physical function. Eur J Pain 2009; 13: 511-517.

34 Shnek ZM, Foley FW, LaRocca NG, Gordon WA, DeLuca J, Schwartzman HG et al. Helplessness, self-efficacy, cognitive distortions, and depression in multiple sclerosis and spinal cord injury. Ann Behav Med 1997; 19: 287-294.

35 Cardenas DD, Hoffman JM, Kelly E, Mayo ME. Impact of a urinary tract infection educational program in persons with spinal cord injury. J Spinal Cord Med 2004; 27 : 47-54.

36 Suzuki R, Krahn GL, McCarthy MJ, Adams EJ. Understanding health outcomes: physical secondary conditions in people with spinal cord injury. Rehabil Psychol 2007: 52: 338-350.

37 Sheppard R, Kennedy P, Mackey CA. Theory of planned behaviour, skin care and pressure sores following spinal cord injury. J Clin Psychol Med Set 2006; 13: 359-367.
38 Spungen MI, Libin A, Ljungberg I, Groah S. Self-efficacy mediating the occurrence of secondary conditions after spinal cord injury. SCI Psychosocial Process 2009; 22 : $16-22$

39 Molton IR, Stoelb BL, Jensen MP, Ehde DM, Raichle KA, Cardenas DD. Psychosocial factors and adjustment to chronic pain in spinal cord injury: replication and crossvalidation. J Rehabil Res Dev 2009; 46: 31-42.

40 Hanley MA, Raichle K, Jensen M, Cardenas DD. Pain catastrophizing and beliefs predict changes in pain interference and psychological functioning in persons with spinal cord injury. J Pain 2008; 9: 863-871.

41 Pang MY, Eng JJ, Lin KH, Tang PF, Hung C, Wang YH. Association of depression and pain interference with disease-management self-efficacy in community-dwelling individuals with spinal cord injury. J Rehabil Med 2009; 41: 1068-1073.

42 Kennedy P, Taylor N, Hindson L. A pilot investigation of a psychosocial activity course for people with spinal cord injuries. Psychol Health Med 2006; 11: 91-99.

43 Tate DG, Forchheimer M. Enhancing community reintegration after inpatient rehabilitation for persons with spinal cord injury. Top Spinal Cord Inj Rehabili 1998; 4: $42-55$

44 Molton IR, Jensen MP, Nielson W, Cardenas D, Ehde DM. A preliminary evaluation of the motivational model of pain self-management in persons with spinal cord injuryrelated pain. J Pain 2008; 9: 606-612.

45 Lannem AM, Sorensen M, Lidal IB, Hjeltnes N. Perceptions of exercise mastery in persons with complete and incomplete spinal cord injury. Spinal Cord 2010; 48: 388-392.

46 Latimer AE, Ginis KAM. The theory of planned behavior in prediction of leisure time physical activity among individuals with spinal cord injury. Rehabil Psychol 2005; 50: 389-396.

47 Latimer AE, Ginis KAM, Arbour KP. The efficacy of an implementation intention intervention for promoting physical activity among individuals with spinal cord injury: a randomized controlled trial. Rehabili Psychol 2006; 51: 273-280.

48 Tun CG, Tun PA, Wingfield A. Cognitive function following long-term spinal cord injury. Rehabil Psychol 1997; 42: 163-182.

49 Horn W, Yoels W, Wallace D, Macrina D, Wrigley M. Determinants of self-efficacy among persons with spinal cord injuries. Disabil Rehabil 1998; 20: 138-141.

50 Nosek MA, Walter LJ. Community integration of women with spinal cord injuries: an examination of psychological, social, vocational, and environmental factors. Top Spinal Cord In Rehabili 1998; 4: 41-55.

51 Gorman C, Kennedy P, Hamilton LR. Alterations in self-perceptions following childhood onset of spinal cord injury. Spinal Cord 1998; 36: 181-185.

52 Buchanan KM, Elias LJ. Personality \& behaviour changes following spinal cord injury: self perceptions-partner's perceptions. Axone 1999; 21: 36-39.

53 McMillen JC, Cook CL. The positive by-products of spinal cord injury and their correlates. Rehabili Psychol 2003; 48: 77-85.

54 Coyle CP, Lesnik-Emas S, Kinney WB. Predicting life satisfaction among adults with spinal cord injuries. Rehabili Psychol 1994; 39: 95-112.

55 Forchheimer M, Tate DG. Enhancing community re-integration following spinal cord injury. Neuro Rehabil 2004; 19: 103-113.

56 Zahl ML, Compton DM, Kim K, Rosenbluth JP. SCI/D forum to increase active living: the effect of a self-efficacy and self-affirmation based SCI/D forum on active living in adults with spinal cord injury/disease. SCI Psychosocial Process 2008; 21 : 5-13.

57 Rose A, Piatt JA, Zahl M, Kim K. The effect of a self-efficacy based forum on life satisfaction for individuals with spinal cord injury or disease. Ann Therapeutic Recreation 2008; 16: 49-56.

58 Arbour-Nicitopoulos KP, Ginis KA, Latimer AE. Planning, leisure-time physical activity, and coping self-efficacy in persons with spinal cord injury: a randomized controlled trial. Arch Phys Med Rehabil 2009; 90: 2003-2011.

59 Perry KN, Nicholas MK, Middleton JW. Comparison of a pain management program with usual care in a pain management center for people with spinal cord injury-related chronic pain. Clin J Pain 2010; 26: 206-216.

60 Zemper ED, Tate DG, Roller S, Forchheimer M, Chiodo A, Nelson VS et al. Assessment of a holistic wellness program for persons with spinal cord injury. Am J Phys Med Rehabil 2003; 82: 957-968; quiz 69-71.

61 Rosenberg M. Society and the Adolescent Self-Image. Princeton University Press: Princeton, NJ, 1965

62 Tzonichaki I, Kleftaras G. Paraplegia from spinal cord injury: self-esteem, loneliness, and life satisfaction. OTJR 2002; 22: 96-103.

63 Mona LR, Krause JS, Norris FH, Cameron RP, Kalichman SC, Lesondak LM. Sexual expression following spinal cord injury. Neuro Rehabil 2000; 15: 121-131.

64 Song HY. Modeling social reintegration in persons with spinal cord injury. Disabil Rehabil 2005; 27: 131-141.

65 Kennedy P, Gorsuch N, Marsh N. Childhood-onset of spinal-cord injury - self-esteem and self-perception. Br J Clin Psychol 1995; 34: 581-588.

66 Blanes L, Carmagnani MI, Ferreira LM. Quality of life and self-esteem of persons with paraplegia living in Sao Paulo, Brazil. Qual Life Res 2009; 18: 15-21.

67 Tate DG, Stiers W, Daugherty J, Forchheimer M, Cohen E, Hansen N. The effects of insurance benefits coverage on functional and psychosocial outcomes after spinal cord injury. Arch Phys Med Rehabil 1994; 75: 407-414.

68 Piazza D, Holcombe J, Foote A, Paul P, Love S, Daffin P. Hope, social support and selfesteem of patients with spinal cord injuries. J Neurosci Nurs 1991; 23: 224-230.

69 Kreuter M, Siosteen A, Biering-Sorensen F. Sexuality and sexual life in women with spinal cord injury: a controlled study. J Rehabil Med 2008; 40: 61-69.

70 Marini I, Rogers L, Slate JR, Vines C. Self-esteem differences among persons with spinal cord injury. Rehabil Counsel Bull 1995; 38: 198-206. 
71 Craig AR, Hancock K, Chang E. The influence of spinal cord injury on coping styles and self-perceptions two years after the injury. Aust N Z J Psychiatry 1994; 28: 307-312.

72 Hancock K, Craig A, Tennant C, Chang E. The influence of spinal cord injury on coping styles and self-perceptions: a controlled study. Aust N Z J Psychiatry 1993; 27: 450-456.

73 Alexander CJ, Hwang K, Sipski ML. Mothers with spinal cord injuries: impact on marital, family, and children's adjustment. Arch Phys Med Rehabil 2002; 83: 24-30.

74 Antle BJ. Factors associated with self-worth in young people with physical disabilities. Health Social Work 2004; 29: 167-175.

75 Craig AR, Hancock K, Dickson H, Chang E. Long-term psychological outcomes in spinal cord injured persons: results of a controlled trial using cognitive behavior therapy. Arch Phys Med Rehabil 1997; 78: 33-38.

76 Antonovsky A. Health, Stress and Coping: New Perspectives on Mental and Physical Well-Being. Jossey-Bass: San Francisco, 1979.

77 Wu MY, Chan F. Psychosocial adjustment patterns of persons with spinal cord injury in Taiwan. Disabil Rehabil 2007; 29: 1847-1857.

78 Lustig DC. The adjustment process for individuals with spinal cord injury: the effect of perceived premorbid sense of coherence. Rehabil Counsel Bull 2005; 48: $146-156$.

79 Kennedy P, Lude P, Elfstrom ML, Smithson E. Sense of coherence and psychological outcomes in people with spinal cord injury: Appraisals and behavioural responses. $\mathrm{Br} J$ Health Psychol 2010; 15(Pt 3): 611-621.

80 Lude $\mathrm{P}$, Kennedy P, Evans M, Lude Y, Beedie A. Post traumatic distress symptoms following spinal cord injury: a comparative review of European samples. Spinal Cord 2005; 43: 102-108.

81 Norrbrink Budh C, Kowalski J, Lundeberg T. A comprehensive pain management programme comprising educational, cognitive and behavioural interventions for neuropathic pain following spinal cord injury. J Rehabil Med 2006; 38: $172-180$

82 Carlozzi BL, Winterowd C, Harrist RS, Thomason N, Bratkovich K, Worth S. Spirituality, anger, and stress in early adolescents. J Religion Health 2010; 49: 445-459.

83 Frankl VE. Man's Search for Meaning. Washington Square Press: New York, 1959.

84 White B, Driver S, Warren AM. Resilience and indicators of adjustment during rehabilitation from a spinal cord injury. Rehabil Psychol 2010; 55: 23-32.

85 de Roon-Cassini TA, de St Aubin E, Valvano A, Hastings J, Horn P. Psychological wellbeing after spinal cord injury: perception of loss and meaning making. Rehabil Psychol 2009; 54: 306-314.

86 Thompson NJ, Coker J, Krause JS, Henry E. Purpose in life as a mediator of adjustment after spinal cord injury. Rehabili Psychol 2003; 48: 100-108.

87 Krause JS, Carter R, Zhai Y, Reed K. Psychologic factors and risk of mortality after spinal cord injury. Arch Phys Med Rehabil 2009; 90: 628-633.

88 Campbell JD, Yoon DP, Johnstone B. Determining relationships between physical health and spiritual experience, religious practices, and congregational support in a heterogeneous medical sample. J Relig Health 2010; 49: 3-17.

89 Johnstone B, Yoon DP. Relationships between the brief multidimensional measure of religiousness/spirituality and health outcomes for a heterogeneous rehabilitation population. Rehabil Psychol 2009; 54: 422-431.

90 Krause JS, Broderick LE, Broyles J. Subjective well-being among African-Americans with spinal cord injury: an exploratory study between men and women. Neuro Rehabil 2004; 19: 81-89.

91 Bruininks P, Malle BF. Distinguishing hope from optimism and related affective states. Motivation Emotion 2005; 29: 324-352.

92 Kortte KB, Gilbert M, Gorman P, Wegener ST. Positive psychological variables in the prediction of life satisfaction after spinal cord injury. Rehabil Psychol 2010; 55: 40-47.

93 Kennedy P, Evans M, Sandhu N. Psychological adjustment to spinal cord injury: the contribution of coping, hope and cognitive appraisals. Psychol Health Med 2009; 14: 17-33.

94 Benony H, Daloz L, Bungener C, Chahraoui K, Frenay C, Auvin J. Emotional factors and subjective quality of life in subjects with spinal cord injuries. Am J Phys Med Rehabil 2002; 81: 437-445.

95 Schmitt MM, Elliott TR. Verbal learning ability and adjustment to recent-onset spinal cord injury. Rehabili Psychol 2004; 49: 288-294.

96 Berry JW, Elliott TR, Rivera P. Resilient, undercontrolled, and overcontrolled personality prototypes among persons with spinal cord injury. J Pers Assess 2007; 89: 292-302.

97 Rohe DE, Krause JS. The five-factor model of personality: findings in males with spinal cord injury. Assessment 1999; 6: 203-214.

98 de Carvalho SA, Andrade MJ, Tavares MA, de Freitas JL. Spinal cord injury and psychological response. Gen Hosp Psychiatry 1998; 20: 353-359.

99 Gioia MC, Cerasa A, Di Lucente L, Brunelli S, Castellano V, Traballesi M. Psychological impact of sports activity in spinal cord injury patients. Scand J Med Sci Sports 2006; 16: 412-416.

100 Webb JR, Toussaint L, Kalpakjian CZ, Tate DG. Forgiveness and health-related outcomes among people with spinal cord injury. Disabil Rehabil 2010; 32: 360-366.

$101 \mathrm{McShane}$ SL, Karp J. Employment following spinal cord injury: a covariance structure analysis. 1993

102 Caldwell LL, Weissinger E. Factors influencing free time boredom in a sample of persons with spinal cord injuries. Therapeutic Recreation J 1994; 28: 18-24.

103 Wickham SE, Hanson CS, Shechtman O, Ashton C. A pilot study: attitudes toward leisure and leisure motivation in adults with spinal cord injury. Occup Ther Health Care 2000; 12: 33-50.
104 Davis M, Matthews B, Jackson WT, Fraser E, Richards JS. Self-concept as an outcome of spinal cord injury: the relation of race, hardiness, and locus of control. SCl Psychosocial Process 1995; 8: 96-101.

105 Swan GE, Carmelli D. Curiosity and mortality in aging adults: a 5-year follow-up of the Western Collaborative Group Study. Psychol Aging 1996; 11: 449-453.

106 Brink A. Curiosity, Personal Growth Initiative, and Life Satisfaction in Older Adults. Proquest, Umi Dissertation Publishing: Ann Arbor, MI 2009.

107 Gallagher MW, Lopez SJ. Curiosity and well-being. J Positive Psychol 2007; 2: 236-248.

108 Kashdan TB, Steger MF. Curiosity and pathways to well-being and meaning in life: Traits, states, and everyday behaviors. Motivation Emotion 2007; 31: 159-173.

109 Jones F, Riazi A. Self-efficacy and self-management after stroke: a systematic review. Disability Rehabil 2011; 33: 797-810.

110 Rottmann N, Dalton So, Christensen J, Frederiksen K, Johansen C. Self-efficacy, adjustment style and well-being in breast cancer patients: a longitudinal study. Quality Life Res Int J Quality Life Aspects Treatment Care Rehabil 2010; 19: 827-836.

111 Strobel M, Tumasjan A, Spörrle M. Be yourself, believe in yourself, and be happy: selfefficacy as a mediator between personality factors and subjective well-being. Scand $J$ Psychol 2011; 52: 43-48.

112 Karademas EC. Self-efficacy, social support and well-being. The mediating role of optimism. Personality Individual Differences 2006; 40: 1281-1290.

113 Vacek KR, Coyle LD, Vera EM. Stress, self-esteem, hope, optimism, and well-being in urban ethnic minority adolescents. J Multicultural Counsel Develop 2010; 38: 99-111.

114 Jemtå L, Fugl-Meyer KS, berg K, Dahl M. Self-esteem in children and adolescents with mobility impairment: impact on well-being and coping strategies. Acta Paediatrica 2009; 98: 567-572.

115 Eriksson M, Lindström B. Antonovsky's sense of coherence scale and the relation with health: a systematic review. J Epidemiol Community Health 2006; 60: 376-381.

116 Eriksson M, Lindström B. Antonovsky's sense of coherence scale and its relation with quality of life: a systematic review. J Epidemiol Community Health 2007; 61: 938-944.

117 Flensborg-Madsen T, Ventegodt S, Merrick J. Coherence and physical health. Scientific World J 2005; 5: 665-673.

118 Lindström B, Eriksson M. Salutogenesis. J Epidemiol Community Health 2005; 59: 440-442.

119 Libera A, Darmochwal-Kolarz D, Oleszczuk J. Sense of coherence (SOC) and styles of coping with stress in women after premature delivery. Med Sci Monit 2007; 13: 125-130.

120 Chida Y, Steptoe A, Powell LH. Religiosity/spirituality and mortality. Psychotherapy Psychosomatics 2009; 78: 81-90.

121 Dew RE, Daniel SS, Armstrong TD, Goldston DB, Triplett MF, Koenig HG. Religion/ spirituality and adolescent psychiatric symptoms: a review. Child Psychiatry Human Develop 2008; 39: 381-398.

122 Dalmida SG. Spirituality, mental health, physical health, and health-related quality of life among women with HIV/AIDS: integrating spirituality into mental health care. Issues Mental Health Nursing 2006; 27: 185-198.

123 Somlai AM, Kelly JA, Kalichman SC, Mulry G, Sikkema KJ, McAuliffe T et al. An empirical investigation of the relationship between spirituality, coping, and emotional distress in people living with HIV infection and AIDS. J Pastoral Care 1996; 50: 181-191.

124 Tuck I, McCain NL, Elswick Jr RK. Spirituality and psychosocial factors in persons living with HIV. J Adv Nursing 2001; 33: 776-783.

125 Boyle PA, Buchman AS, Barnes LL, Bennett DA. Effect of a purpose in life on risk of incident Alzheimer disease and mild cognitive impairment in community-dwelling older persons. Arch Gen Psychiatry 2010; 67: 304-310.

126 Hedberg P, Gustafson Y, Alèx L, Brulin C. Depression in relation to purpose in life among a very old population: a five-year follow-up study. Aging Mental Health 2010; 14: 757-763.

127 Nygren B, Aléx L, Jonsén E, Gustafson Y, Norberg A, Lundman B. Resilience, sense of coherence, purpose in life and self-transcendence in relation to perceived physical and mental health among the oldest old. Aging Mental Health 2005; 9: 354-362.

128 Heisel MJ, Flett GL. Purpose in life, satisfaction with life, and suicide ideation in a clinical sample. J Psychopathol Behav Assess 2004; 26: 127-135.

129 French S, Joseph S. Religiosity and its association with happiness, purpose in life, and self-actualisation. Mental Health Religion Culture 1999; 2: 117-120.

130 Post BC, Wade NG. Religion and spirituality in psychotherapy: a practice-friendly review of research. J Clin Psychol 2009; 65: 131-146.

131 Gibson C, Tomarken A, Breitbart W. Meaning-centered group psychotherapy for cancer patients. In: Puchalski CM (ed) A Time for Listening and Caring: Spirituality and the Care of the Chronically III and Dying. Oxford University Press: New York, NY, 2006 pp 269-282.

132 Breitbart W, Gibson C, Poppito SR, Berg A. Psychotherapeutic interventions at the end of life: a focus on meaning and spirituality. Can J Psychiatry/La Revue canadienne de psychiatrie 2004; 49: 366-372.

133 Lee V, Cohen SR, Edgar L, Laizner AM, Gagnon AJ. Meaning-making intervention during breast or colorectal cancer treatment improves self-esteem, optimism, and selfefficacy. Social Sci Med 2006; 62: 3133-3145.

134 Scheier MF, Carver CS, Bridges MW. Optimism, pessimism, and psychological wellbeing. In: Chang EC (ed) Optimism \& Pessimism: Implications for Theory, Research, and Practice. American Psychological Association: Washington, DC, 2001, pp 189-216. 
135 Kersten P, Ellis-Hill C, McPherson KM, Harrington R. Beyond the RCT- understanding the relationship between interventions, individuals and outcome - the example of neurological rehabilitation. Disabil Rehabil 2010; 32: 1028-1034.

136 Marks R, Allegrante JP, Lorig K. A review and synthesis of research evidence for selfefficacy-enhancing interventions for reducing chronic disability: implications for health education practice (part I). Health Promotion Practice 2005; 6: 37-43.

137 Marks R, Allegrante JP, Lorig K. A review and synthesis of research evidence for selfefficacy-enhancing interventions for reducing chronic disability: implications for health education practice (part II). Health Promotion Practice 2005; 6: 148-156.

138 Visser A, Garssen B, Vingerhoets A. Spirituality and well-being in cancer patients: review. Psycho-Oncology 2010; 19: 565-572.

139 Ruch W, Proyer RT, Weber M. Humor as a character strength among the elderly: empirical findings on age-related changes and its contribution to satisfaction with life. Zeitschrift für Gerontologie und Geriatrie 2010; 43: 13-18.

140 Sherer M. The self-efficacy scale: construction and validation. Psychol Rep 1982; 51: 663-671.

141 Schwarzer R, Jerusalem M. Generalized self-efficacy scale. In: Weinman J, Wright S, Johnston M (eds) Measures in Health Psychology: A User's Portfolio Causal and Control Beliefs. NER-NELSON: Windsor, England, 1995 pp. 35-37.

142 McMillen JC, Fisher RH. The perceived benefit scales: measuring perceived positive life changes after negative events. Social Work Res 1998; 22: 173-186.

143 Lorig K, Stewart A, Ritter P, González V, Laurent D, Lynch J. Outcome Measures for Health Education and Other Health Care Interventions. Sage Publications: Thousand Oaks, 1996.

144 Becker H, Stuifbergen A, Ingalsbe K, Sands D. Health promoting attitudes and behavior among persons with disabilities. Int/ J Rehabil Res 1989; 12: 235-250.

145 Smith MS, Wallston KA, Smith CA. The development and validation of the perceived health competence scale. Health Edu Res 1995; 10: 51-64.

146 Nicholas MK. The pain self-efficacy questionnaire: taking pain into account. Eur $J$ Pain 2007; 11: 153-163.

147 Middleton JW, Tate RL, Geraghty TJ. Self-efficacy and spinal cord injury: psychometric properties of a new scale. Rehabil Psychol 2003; 48: 281-288.

148 Schiaffino KM, Revenson TA, Gibofsky A. Assessing the impact of self-efficacy beliefs on adaptation to rheumatoid arthritis. Arthritis Care Res 1991; 4: 150-157.

149 Tawashy AE, Eng JJ, Lin KH, Tang PF, Hung C. Physical activity is related to lower levels of pain, fatigue and depression in individuals with spinal-cord injury: a correlational study. Spinal Cord 2009; 47: 301-306.

150 Kroll T, Kehn ME, Ho P, Groah SA. The SCl Exercise Self-efficacy Scale (ESES): development and psychometric properties. Int J Behav Nutr Phys Activity 2007; 4: 34.

151 Tellegen A Brief Manual for the Differential Personality Questionnaire: Unpublished manuscript; 1982

152 Krause JS. Personality and traumatic spinal cord injury: relationship to participation in productive activities. J Appl Rehabil Counsel 1997; 28: 15-20.

153 Pearlin LI, Schooler C. The structure of coping. J Health Social Behav 1978; 19: 2-21.

154 Jensen MP, Turner JA, Romano JM, Lawler BK. Relationship of pain-specific beliefs to chronic pain adjustment. Pain 1994; 57: 301-309.

155 Jensen MP, Keefe FJ, Lefebvre JC, Romano JM, Turner JA. One- and two-item measures of pain beliefs and coping strategies. Pain 2003; 104: 453-469.

156 Nosek MA, Fuhrer MJ. Independence among people with disabilities: I. A heuristic model. Rehabil Counsel Bull 1992; 36: 6-20.
157 Cohen S, Kamarck T, Mermelstein R. A global measure of perceived stress. J Health Social Behav 1983; 24: 385-396.

158 Armitage CJ, Conner M. Distinguishing perceptions of control from self-efficacy: predicting consumption of a low-fat diet using the theory of planned behavior. J Appl Social Psychol 1999; 29: 72-90.

159 Sørensen M. The Psychology of Initiating and Maintaining Exercise and Diet Behaviour. University of Bergen: Bergen, 1997.

160 Lannem AM, Sorensen M, Froslie KF, Hjeltnes N. Incomplete spinal cord injury, exercise and life satisfaction. Spinal Cord 2009; 47: 295-300.

161 Witt PA, Ellis GD. The Leisure Diagnostic Battery Users Manual. Venture: State College, PA, 1989.

162 Lee Y. Does self-monitoring influence the experience of leisure for individuals with spinal cord injury? Ann Therapeutic Recreation 2008; 16: 39-48.

163 Rotter JB. Generalized expectancies for internal versus external control of reinforcement. Psychol Monographs Gen Appl 1966; 80: 1-28.

164 Hall KM, Knudsen ST, Wright J, Charlifue SW, Graves DE, Werner P. Follow-up study of individuals with high tetraplegia (C1-C4) 14 to 24 years postinjury. Arch Phys Med Rehabil 1999; 80: 1507-1513.

165 Battle J. Culture-Free Self-Esteem Inventories for Children and Adults. Special Child Publications: Seattle, WA, 1981.

166 Hudson WW. The Clinical Measurement Package: A Field Manual. Dorsey: Chicago, 1982.

167 Snell WE, Papini DR. The sexuality scale: an instrument to measure sexual-esteem, sexual-depression, and sexual-preoccupation. J Sex Res- 1989; 26: 256-263.

168 Triandis HC, Bontempo R, Betancourt H, Bond M. The measurement of the etic aspects of individualism and collectivism across cultures. Aus J Psychol 1986; 38: 257-267.

169 Harter S. The Self-Perception Profile for Adolescents. University of Denver: Denver, 1988.

170 Crumbaugh JC, Maholick LT. An experimental study in existentialism: the psychometric approach to Frankl's concept of noogenic neurosis. J Clin Psychol 1964; 20: 200-207.

171 Battista J, Almond R. The development of meaning in life. Psychiatry J Study Interpersonal Processes 1973; 36: 409-427.

172 Hodge DR. The intrinsic spirituality scale: a new six-item instrument for assessing the salience of spirituality as a motivational construct. J Social Service Res 2003; 30: 41-61.

173 Miller JF, Powers MJ. Development of an instrument to measure hope. Nurs Res 1988; 37: 6-10.

174 Watson M, Greer S, Bliss J. Mental Adjustment to Cancer (MAC) Scale: Users' Manual. Royal Marsden Hospital. CRC Psychological Medicine Research Group: Surrey, UK, 1989.

175 Snyder CR, Sympson SC, Ybasco FC, Borders TF, Babyak MA, Higgins RL. Development and validation of the state hope scale. J Personality Social Psychol 1996; 70: 321-335.

176 Snyder CR, Harris C, Anderson JR, Holleran SA, Irving LM, Sigmon ST et al. The will and the ways: development and validation of an individual-differences measure of hope. J Personality Social Psychol 1991; 60: 570-585.

177 Carver CS, Scheier MF, Weintraub JK. Assessing coping strategies: a theoretically based approach. J Personality Social Psychol 1989; 56: 267-283.

178 Brooks DN, McKinlay WW. Personality and behavioural change after severe blunt head injury: a relative's view. J Neurol Neurosurg Psychiatry 1983; 46: 336-344.

Supplementary Information accompanies the paper on the Spinal Cord website (http://www.nature.com/sc) 